\title{
Biodegradation kinetics of acenaphthene by Sphingobacterium sp. strain RTSB isolated from a petroleum-contaminated soil
}

\author{
Somnath Mallick* \\ Department of Chemistry, Sreegopal Banerjee College, Bagati, Magra, Hooghly 712 148, India
}

\begin{abstract}
Acenaphthene metabolism was previously reported by a Gram-negative Sphingobacterium sp. strain RTSB. The degradation pathway was found to proceed involving the key intermediate 1-naphthoic acid and processed via trans-3-carboxy-2-hydroxybenzylidenepyruvic acid to salicylic acid and catechol. The present article demonstrates the biodegradation kinetics of acenaphthene along with the fate of some of the major metabolites, 1-naphthoic acid, 1-acenaphthenol, 1-acenaphthenone, acenaphthenequinone, salicylic acid, and catechol; where, the maximum accumulated amount of 1-naphthoic acid measured was $302.1 \mathrm{mg} \mathrm{l}^{-1}$ during the mid-log stage of growth. The degradation of acenaphthene was observed to follow a first order kinetic model with a rate constant $0.528 \mathrm{~d}^{-1}$ and halflife of 1.31 days.
\end{abstract}

Keywords: Acenaphthene, biodegradation, kinetic study, 1-naphthoic acid, Sphingobacterium sp.

POLYCYCLIC aromatic hydrocarbons (PAHs) include a cluster of widely present contaminants due to their potential carcinogenic, mutagenic, and/or toxic properties ${ }^{1-3}$. PAHs are considered persistent organic pollutants because of their high stability and hydrophobic nature, and because of these, cleaning up of sites polluted with PAHs by conventional techniques are somewhat difficult. Consequently, bioremediation studies of PAHs have acquired substantial interest nowadays and numerous microorganisms capable of degrading diverse PAH molecules have been reported ${ }^{4-8}$.

According to the U.S. Environmental Protection Agency, acenaphthene is considered as one of the 16 priority $\mathrm{PAH}$ pollutants $^{9}$ and released in the ambience primarily by anthropogenic and pyrolytic processes in addition to emissions and effluents from different industries ${ }^{10,11}$. In recent years, extensive use of acenaphthene in several industries ${ }^{11}$ resulted in their high level discharge and accumulation in the environment, which caused an alarming concern among the environmental scientists. In the past few decades, acenaphthene bioremediation studies involving

*e-mail: somnathmallick@yahoo.com various bacterial sp. had gained great interest and were reported $^{10,12-24}$. There are diverse reports of acenaphthene assimilation by a solitary isolate being able to degrade acenaphthene as the individual carbon source ${ }^{15,18,19,22-24}$ along with co-metabolism studies ${ }^{10,12,24,25}$; and depending on the bacterial sp. under examination, numerous metabolic pathways exist. In an earlier study, a comprehensive report of acenaphthene biodegradation was made by Sphingobacterium sp. strain RTSB via 1-naphthoic acid, which was then degraded via trans-3-carboxy-2-hydroxybenzylidenepyruvic acid to salicylic acid and catechol ${ }^{19}$.

Even though aerobic biodegradation is a vital technique for the atmospheric reduction of PAHs, potential estimation of $\mathrm{PAH}$ biodegradation rates is more significant to predict environmental destiny as well as to manipulate bioremediation efforts. Information related to biodegration rate is very much desired for metabolic regulation and engineering of $\mathrm{PAH}$ assimilation pathways as well as for the enhancement of degradation competence. Although there are several reports of biodegradation studies of acenaphthene by different microorganisms, neither of them revealed any detailed kinetic study of the degradation pathway. In this study, both kinetic and metabolic aspects of acenaphthene biodegradation and the outcome of metabolic intermediate 1-naphthoic acid together with other metabolites, viz. 1-acenaphthenol, 1acenaphthenone, acenaphthenequinone, salicylic acid and catechol were explored in the acenaphthene degradation pathway by Sphingobacterium sp. strain RTSB. Therefore, the present study may be useful in refining the competence of acenaphthene degradation along with other PAHs and to remediate the environment contaminated with PAHs.

\section{Materials and methods}

\section{Isolation of the bacterial strain}

Isolation of the Sphingobacterium sp. strain RTSB, a novel acenaphthene degrading bacterium, was carried out by enrichment culture technique ${ }^{19}$ from the soil contaminated with petroleum with acenaphthene $\left(1 \mathrm{~g} \mathrm{l}^{-1}\right)$, as the solitary carbon and energy resource. 


\section{Media and culture conditions}

Growth of the bacterial cells was carried out in a liquid mineral salt medium (MSM, $\mathrm{pH}$ 7.2) containing $3.34 \mathrm{~g}$ $\mathrm{K}_{2} \mathrm{HPO}_{4}, 2.0 \mathrm{~g} \mathrm{NH}_{4} \mathrm{Cl}, 0.87 \mathrm{~g} \mathrm{NaH}_{2} \mathrm{PO}_{4}, 200 \mathrm{mg} \mathrm{MgSO}$. $7 \mathrm{H}_{2} \mathrm{O}, 123 \mathrm{mg}$ nitrilotriacetic acid, $12 \mathrm{mg} \mathrm{FeSO}_{4} \cdot 7 \mathrm{H}_{2} \mathrm{O}$, $3 \mathrm{mg} \mathrm{ZnSO}_{4} \cdot 7 \mathrm{H}_{2} \mathrm{O}, 3 \mathrm{mg} \mathrm{MnSO}_{4} \cdot \mathrm{H}_{2} \mathrm{O}$ and $1 \mathrm{mg} \mathrm{CoCl}_{2}$. $6 \mathrm{H}_{2} \mathrm{O}$ per litre.

\section{Degradation experiments}

Acenaphthene degradation experiments were conducted at $28^{\circ} \mathrm{C}$ on a rotating shaker $(180 \mathrm{rpm})$ in a $100 \mathrm{ml}$ conical flask having $25 \mathrm{ml}$ of MSM (pH 7.2) supplemented with acenaphthene $\left(1 \mathrm{~g} \mathrm{l}^{-1}\right)$ as the solitary source of carbon, and the resultant metabolites of the acenaphthene degradation pathway were isolated and recognized by combined chromatographic and spectrometric techniques ${ }^{19}$. To optimize the conditions of acenaphthene assimilation by the strain RTSB, replicate bacterial cultures in MSM with $1 \mathrm{~g} \mathrm{l}^{-1}$ of acenaphthene were incubated at different incubation temperatures and $\mathrm{pH}$ values in the range of $22^{\circ} \mathrm{C}$ to $42^{\circ} \mathrm{C}$, and 5.0 to 9.0 respectively. The degradation process was monitored with different preliminary acenaphthene concentrations $\left(0.05-5.0 \mathrm{~g}^{-1}\right)$ and incubated for diverse periods at optimized temperature and $\mathrm{pH}$. To estimate the remaining acenaphthene in the culture medium at each sampling point, a spent broth was centrifuged at $8000 \mathrm{~g}$ for $12 \mathrm{~min}$ and the $\mathrm{pH}$ of supernatant liquids was adjusted to $1.5-2.0$ by concentrated $\mathrm{HCl}$. The reaction mixtures were then extracted thrice with ethyl acetate, dried, and evaporated under reduced pressure at $40^{\circ} \mathrm{C}$; and the residual acenaphthene in the medium was quantified through HPLC analysis.

For the measurement of 1-naphthoic acid degradation, the substrate was supplemented in the range of 0.05 $1.0 \mathrm{~g} \mathrm{l}^{-1}$; whereas in the other experimentation, $0.1 \mathrm{~g} \mathrm{l}^{-1}$ of 1-naphthoic acid was added in each installment (total $0.6 \mathrm{~g}^{-1}$ of 1-naphthoic acid) at $24 \mathrm{~h}$ intervals. Acenaphthene and 1-naphthoic acid degradation experiments were conducted with $1 \%$ inoculums $\left(\mathrm{OD}_{660}\right.$ adjusted to 0.5$)$ and $2 \%$ inoculums $\left(\mathrm{OD}_{600}\right.$ adjusted to 0.25$)$ respectively, when incubated with acenaphthene $\left(1 \mathrm{~g} \mathrm{l}^{-1}\right)$ for $72 \mathrm{~h}$ and 1-naphthoic acid $\left(0.5 \mathrm{~g} \mathrm{l}^{-1}\right)$ for $48 \mathrm{~h}$. Based on the amount of cellular protein, cell growth was estimated according to the process of Lowry et $\mathrm{al}^{26}$. Unless mentioned otherwise, all experiments were carried out in triplicate sets.

\section{Analysis and quantification of the metabolites}

Following incubation, at different time intervals, centrifugation of both the spent broth and resting cell cultures were performed at $8000 \mathrm{~g}$ for $12 \mathrm{~min}$ and extracted with ethyl acetate thrice after adjusting the $\mathrm{pH}$ of the supernatants to $1.5-2.0$ by concentrated $\mathrm{HCl}$. Later, the extracts obtained were combined, dried out, and evaporated under reduced pressure at $40^{\circ} \mathrm{C}$ and the resultant residues were used for further analyses. Characterization and quantification of acenaphthene, 1-naphthoic acid, and the resulting metabolites were carried out using HPLC system (Waters Corp., USA) equipped with a $5 \mu \mathrm{m}, 4.6 \mathrm{~mm} \times$ $250 \mathrm{~mm}$ analytical Inertsil ODS-3 column (MetaChem Technologies, Germany), fitted-out through a protector column filled with an identical immobile phase and connected to a Waters 515 solvent supply arrangement. Elution of the metabolites was performed employing a planned gradient of a methanol-water solvent system at a flow speed of $1.0 \mathrm{ml}$ per min and detected at $254 \mathrm{~nm}$ by a 486 adjustable absorbance UV detector (Waters). The movable phase was a linear gradient (45 $\mathrm{min}$ ) from $45 \%$ $(\mathrm{v} / \mathrm{v})$ to $95 \%(\mathrm{v} / \mathrm{v})$ of aqueous methanol, withholding at $90 \%$ for $10 \mathrm{~min}$, and subsequently $95 \%$ to $45 \%(\mathrm{v} / \mathrm{v})$ of the same solvent system within 5 min. By comparing the retention times with that of the authentic compounds analysed in identical conditions, the eluted metabolites were identified. The quantity of unaltered acenaphthene along with residual and/or accumulated 1-naphthoic acid and other metabolites were also measured employing HPLC analyses using version 2.15.01 of the Millennium Session Manager Software package ${ }^{19}$. Without any refinement, analytical grade acenaphthene, 1-naphthoic acid along with other chemicals and reagents were used to carry out all the experiments.

\section{Results and discussion}

An acenaphthene-degrading bacterial strain RTSB was isolated from a petroleum-polluted soil and was identified as Sphingobacterium sp. Isolation and categorization of diverse metabolites recommended the conversion of acenaphthene through 1-naphthoic acid via 1-acenaphthenol, 1 -acenaphthenone, and acenaphthenequinone in the upper stage of assimilation; followed by the transformation of 1-naphthoic acid to salicylic acid and catechol through trans-3-carboxy-2-hydroxybenzylidenepyruvic acid, ultimately entering into the TCA cycle intermediates ${ }^{19}$. It is the first comprehensive report of acenaphthene assimilation with a Sphingobacterium sp. strain, competent of utilizing acenaphthene as the only carbon source; where, within $120 \mathrm{~h}$ of incubation, over $90 \%$ acenaphthene was found to be degraded.

Acenaphthene degradation experiments were performed at different incubation temperatures and $\mathrm{pH}$ values in the array of $22^{\circ} \mathrm{C}$ to $42^{\circ} \mathrm{C}$ (Figure $1 \mathrm{a}$ ) and 5.0 to 9.0 (Figure $1 \mathrm{~b})$ respectively, to optimize the condition of acenaphthene assimilation by the strain RTSB (with optimum $1 \mathrm{~g} \mathrm{l}^{-1}$ acenaphthene concentration). The optimal circumstances for the growth of Sphingobacterium sp. strain RTSB with acenaphthene $\left(1 \mathrm{~g} \mathrm{l}^{-1}\right)$ were set on as $28^{\circ} \mathrm{C}$ and $\mathrm{pH} 7.2$ in a shake culture situation at $180 \mathrm{rpm}$. 



Figure 1. Growth of acenaphthene by Sphingobacterium sp. strain RTSB in MSM (a) at different incubation temperatures ( $\boldsymbol{a})$ and $(\boldsymbol{b})$ different $\mathrm{pH}$ values $(\mathrm{O})$ with initial acenaphthene concentration of $1 \mathrm{~g} \mathrm{l^{-1 }}$. The errors of three independent samples are indicated by bars.
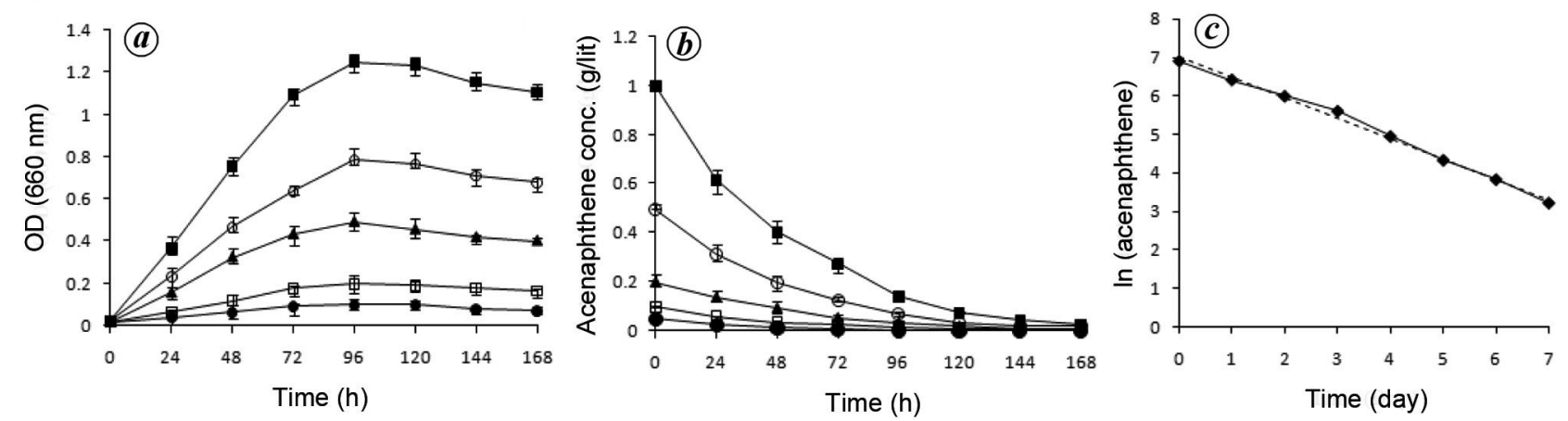

Figure 2. (a) Growth and (b) degradation of acenaphthene by Sphingobacterium sp. strain RTSB in MSM at different initial acenaphthene concentrations of $0.05 \mathrm{~g} \mathrm{l}^{-1}(\bullet), 0.1 \mathrm{~g} \mathrm{l}^{-1}(\square), 0.2 \mathrm{~g} \mathrm{l}^{-1}(\boldsymbol{\Delta}), 0.5 \mathrm{~g} \mathrm{l}^{-1}(\mathrm{O})$, and $1 \mathrm{~g} \mathrm{l}^{-1}(\boldsymbol{\square})$, (c) Plot of the natural logarithm of acenaphthene concentration against degradation time by Sphingobacterium sp. strain RTSB. The errors of three independent samples are indicated by bars.

Growth summary of Sphingobacterium sp. strain RTSB in the course of acenaphthene assimilation at diverse preliminary concentrations is represented in Figure $2 a$. The doubling time found was $32.18,31.26,29.96,28.32$ and $26.27 \mathrm{~h}$ respectively, during bacterial growth with 0.05 , $0.1,0.2,0.5$ and $1 \mathrm{~g} \mathrm{l}^{-1}$ of initial acenaphthene concentrations in MSM medium. The precise growth rate observed was $0.0327,0.0341,0.0362,0.0391$ and $0.0423 \mathrm{~h}^{-1}$ respectively, under similar set of initial acenaphthene concentrations. Figure $2 b$ describes the condition of acenaphthene at the time of incubation by Sphingobacterium sp. strain RTSB at various preliminary concentrations of the substrate. At the time of cultivation, bacterial degradation of acenaphthene encountered a linear decline phase associated with the log-phase growth of Sphingobacterium sp. strain RTSB, when a linear correlation was observed among acenaphthene depletion rates and the primary acenaphthene concentration. The plot of the normal logarithm of acenaphthene concentration against time shown in Figure $2 c$ is linear $\left(R^{2}=0.9947\right)$ under ex- perimental setting and is appropriate to the Monod firstorder kinetic equation ${ }^{27}$ as $\ln C=-K t+A$, where $C, t, K$ and $A$ represent the acenaphthene concentration, time, first-order rate constant and a constant respectively. The rate constant $K$ and the constant $A$ determined from the experimental outcome were $0.528 \mathrm{~d}^{-1}$ and 7.536 respectively. Consequently, the first-order equation might be demonstrated as $\ln C=-0.528 \mathrm{t}+7.536$ and the half-life $\left(t^{1 / 2}=0.693 / \mathrm{K}\right)$ was $1.31 \mathrm{~d}$. Therefore, in this case, acenaphthene assimilation by Sphingobacterium sp. strain RTSB is predicted to follow first-order reaction kinetics.

A steady increase in acenaphthene degradation rate was primarily noticed with an augment in initial acenaphthene concentration up to $1 \mathrm{~g} \mathrm{l}^{-1}$. A rapid fall of acenaphthene concentration was observed in the beginning phase of incubation followed by stagnation. Assimilation of acenaphthene by bacterial cells along with the adsorption of substrate to the cell wall could be the possible reason behind this type of speedy primary decline of the concentration $^{28-30}$. However, the relative assimilation rate of 

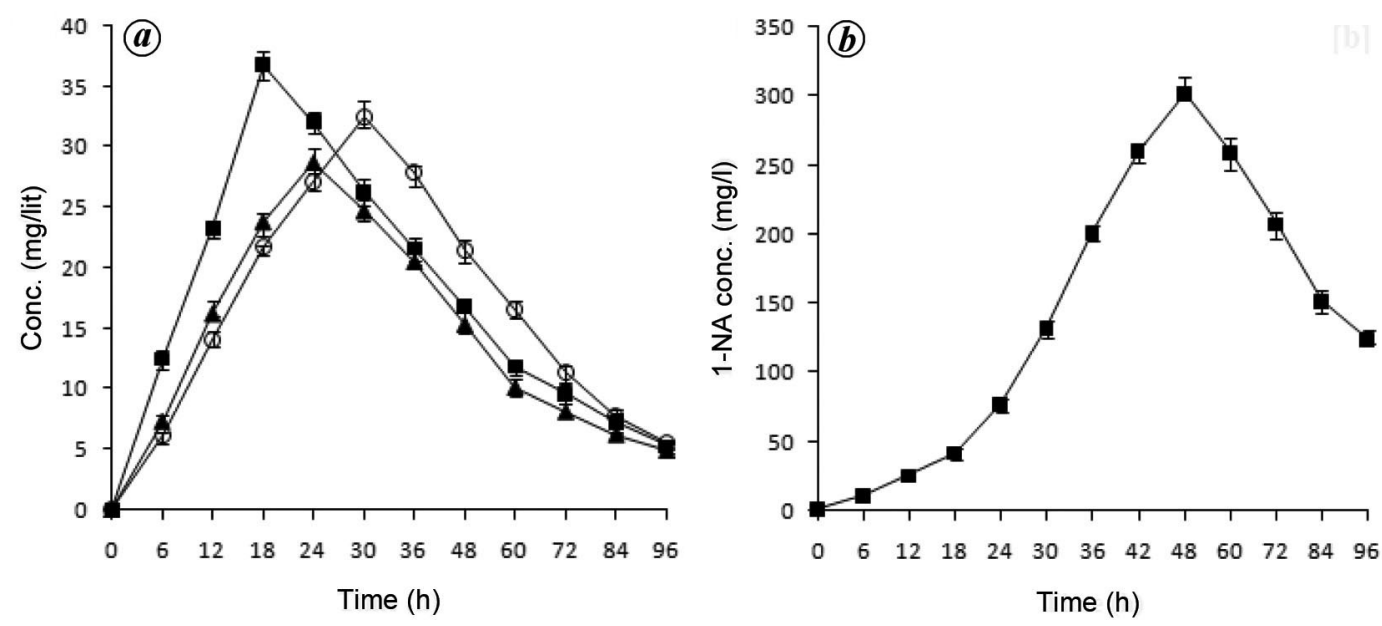

Figure 3. Accumulation and utilization of (a) 1-acenaphthenol ( $\boldsymbol{\square})$, 1-acenaphthenone (A) and acenaphthenequinone (O) and (b) 1-naphthoic acid ( $\boldsymbol{\square})$ during incubation of acenaphthene up to $96 \mathrm{~h}$ by Sphingobacterium sp. strain RTSB in MSM with initial acenaphthene concentration of $1 \mathrm{~g}^{-1}$. The errors of three independent samples are indicated by bars.

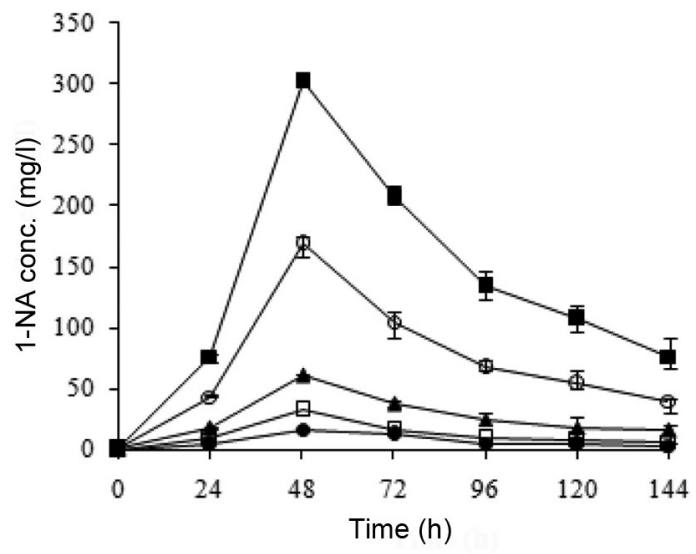

Figure 4. Accumulation along with the utilization of 1-naphthoic acid during incubation of acenaphthene up to $144 \mathrm{~h}$ by Sphingobacterium sp. strain RTSB in MSM at diverse preliminary acenaphthene concentrations. The symbols are identical as in Figure 2.

acenaphthene (per gram) falls steadily ahead of $1 \mathrm{~g}^{-1}$ of concentration; and a severe decrease in its degradation rate was observed over $5 \mathrm{~g} \mathrm{l}^{-1}$ of its primary concentration. The declining rate of biodegradation of acenaphthene ahead of $1 \mathrm{~g} \mathrm{l}^{-1}$ of concentration maybe because of the accumulation of increased levels of 1-naphthoic acid and other toxic metabolites generated at the time of the degradation process. Formation and utilization of various metabolites in the earlier stages of acenaphthene degradation, viz. 1-acenaphthenol, 1-acenaphthenone and acenaphthenequinone, involved in the conversion of acenaphthene to 1-naphthoic acid were monitored kinetically using $1 \mathrm{~g} \mathrm{l}^{-1}$ of initial acenaphthene concentration (Figure $3 a$ ). It was observed that the maximum amount of 1acenaphthenol, 1-acenaphthenone and acenaphthenequinone accumulated was $36.8(18 \mathrm{~h}), 28.7(24 \mathrm{~h})$, and 32.5 $(30 \mathrm{~h}) \mathrm{mg} \mathrm{l}^{-1}$ respectively and simultaneously the amount of 1-naphthoic acid accumulated was 41.9 (18 h), $76.9(24 \mathrm{~h})$, and $132.5(30 \mathrm{~h}) \mathrm{mg} \mathrm{l}^{-1}$ respectively (Figure $3 b$ ).

Figure 4 denotes 1-naphthoic acid accumulation and utilization trends by the strain RTSB in acenaphthene degradation pathway. It was observed that the maximum accumulation of 1-naphthoic acid occurred in the mid-log stage of growth regardless of primary acenaphthene concentration, and the highest amount of accumulated 1-naphthoic acid quantified was $302.1 \mathrm{mg} \mathrm{l}^{-1}$ (with $1 \mathrm{~g} \mathrm{l}^{-1}$ of initial acenaphthene concentration). It was also observed that, with the rise in initial acenaphthene concentration, the amount of accumulated 1-naphthoic acid also increased (457.7 and $638.3 \mathrm{mg} \mathrm{l}^{-1}$ with 2 and $4 \mathrm{~g} \mathrm{l}^{-1}$ of initial acenaphthene concentrations respectively). The accumulation of 1-naphthoic acid in the mid-log phase was perhaps ascribed by the fact that the genetic basics accountable for the assimilation of acenaphthene to 1naphthoic acid and metabolism of 1-naphthoic acid via the metabolite trans-3-carboxy-2-hydroxybenzylidenepyruvic $\operatorname{acid}^{19}$, be in two diverse degradative operons, and the dissimilar metabolic directive of these two operons result in the accumulation of the said metabolite. Since acenaphthene is solely processed via 1-naphthoic acid, it can be perhaps concluded that the action and/or expression of the group of enzymes involved earlier, that transform acenaphthene to 1-naphthoic acid is higher than that of the set of enzymes associated in the lower degradation pathway ${ }^{19}$. However, ahead of the mid-log stage, a steady reduction of 1-naphthoic acid concentration was observed possibly due to low availability of its precursor acenaphthene in the culture medium as well as due to the existence of elevated concentration of enzymes concerned in the ring-cleavage of 1-naphthoic acid.

It was reported earlier that Sphingobacterium sp. strain RTSB grown on acenaphthene showed a positive 

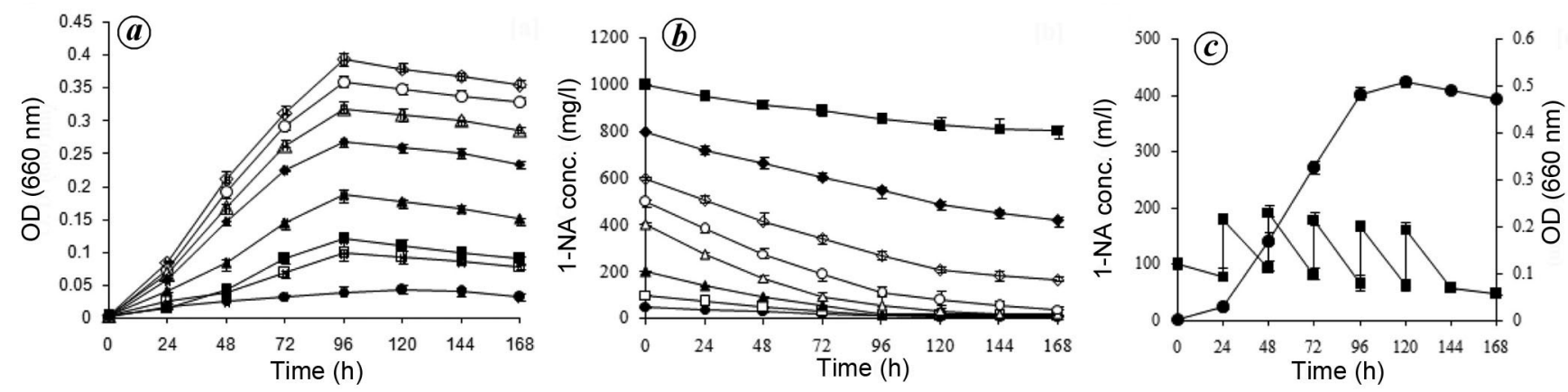

Figure 5. (a) Growth and (b) degradation of 1-naphthoic acid acenaphthene by Sphingobacterium sp. strain RTSB in MSM at various initial 1-naphthoic concentrations of $0.05 \mathrm{~g} \mathrm{l}^{-1}(\bullet), 0.1 \mathrm{~g} \mathrm{l}^{-1}(\square), 0.2 \mathrm{~g} \mathrm{l}^{-1}(\boldsymbol{\Delta}), 0.4 \mathrm{gl}^{-1}(\Delta), 0.5 \mathrm{~g} \mathrm{l}^{-1}(0), 0.6 \mathrm{~g} \mathrm{l}^{-1}(\diamond), 0.8 \mathrm{~g} \mathrm{l}^{-1}(\bullet)$ and $1 \mathrm{~g} \mathrm{l}^{-1}(\boldsymbol{\nabla}),(\boldsymbol{c})$ Growth $(\bullet)$ and degradation $(\boldsymbol{\square})$ of 1-naphthoic $\left(0.6 \mathrm{~g} \mathrm{l}^{-1}\right)$ supplemented in installments, $0.1 \mathrm{~g} \mathrm{l}^{-1}$ at $24 \mathrm{~h}$ intervals.
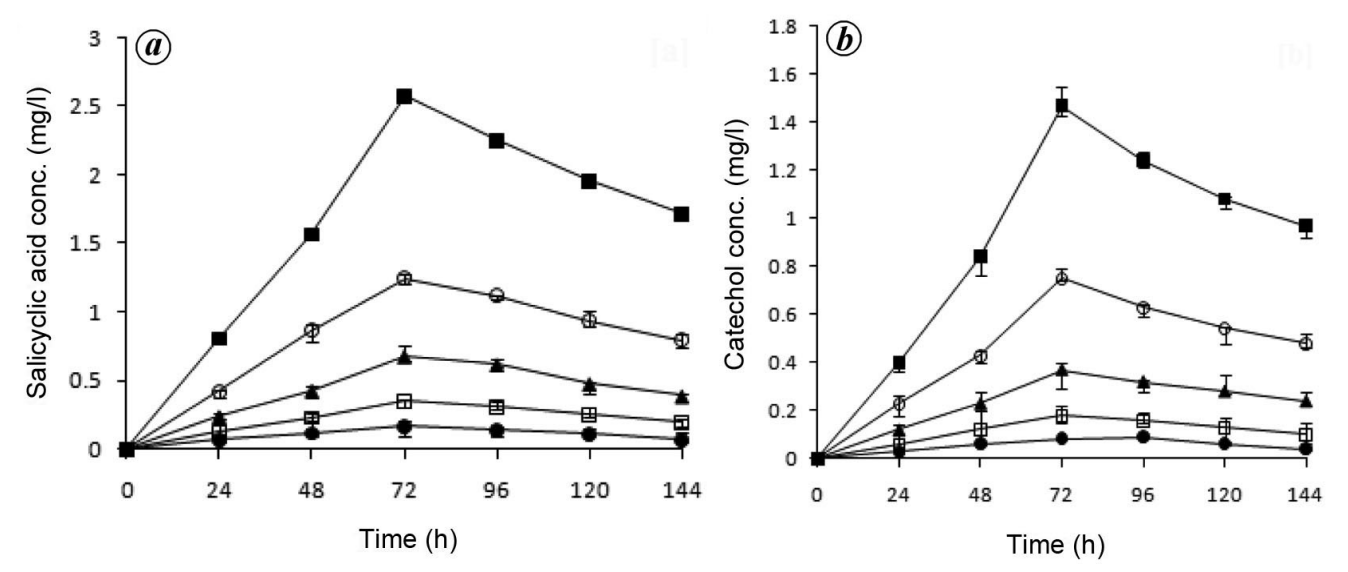

Figure 6. Accumulation and utilization of salicylic acid (a) and catechol (b) during incubation of acenaphthene by Sphingobacterium sp. strain RTSB in MSM at different preliminary acenaphthene concentrations. The symbols are identical as in Figure 2.

response in oxygen uptake studies, as well as it could utilize 1-naphthoic acid as the growth substrate ${ }^{19}$. Figure $5 \mathrm{a}$ illustrates the growth curve of RTSB at different initial concentrations of 1 -naphthoic acid $(0.05,0.1,0.2$, $0.4,0.5,0.6,0.8$ and $\left.1 \mathrm{~g} \mathrm{l}^{-1}\right)$ as the growth substrate, while the biodegradative outcome of 1-naphthoic acid at the time of incubation (taking the same set of substrate concentration) is represented in Figure $5 \mathrm{~b}$. It was seen that with an initial increase of 1-naphthoic acid concentration up to $0.6 \mathrm{~g} \mathrm{l}^{-1}$, the growth increases. However, a steady decrease in growth was documented with an additional raise in the concentration. A possible toxicity of the substrate at an elevated preliminary concentration to the organism could be the reason behind this type of decline in growth. This fact was also supported by the observation that the fall in 1-naphthoic acid concentration was quite steady at low primary concentration, but at an elevated concentration, the lowering was less steady. This observation was confirmed by adding $0.6 \mathrm{~g} \mathrm{l}^{-1}$ of 1-naphthoic acid in installments (with $0.1 \mathrm{~g} \mathrm{l}^{-1}$ in six installments) at $24 \mathrm{~h}$ intervals (Figure $5 \mathrm{c}$ ), when $30.2 \%$ more growth yield was observed compared to that when the same amount $\left(0.6 \mathrm{~g} \mathrm{l}^{-1}\right)$ was added at once at zero hour. In addition to 1-naphthoic acid, fate of the two additional metabolites downstream of the acenaphthene degradation pathway, namely salicylic acid and catechol, was also investigated (Figure 6). Salicylate hydroxylase mediated conversion of salicylic acid to catechol was observed in this case, which subsequently metabolized to 2-hydroxymuconaldehyde acid by the activity of catechol-2,3-dioxygenase, finally forming TCA cycle intermediates ${ }^{19}$. The accumulated amount of salicylic acid and catechol observed was 2.58 and $1.47 \mathrm{mg} \mathrm{l}^{-1}$ respectively after $72 \mathrm{~h}$ of incubation with $1 \mathrm{~g} \mathrm{l}^{-1}$ of acenaphthene. Very low amounts of accumulation of these two metabolites were due to the high level activities of 3-formylsalicylate oxidase and catechol-2,3-dioxygenase ${ }^{19}$.

\section{Conclusion}

The kinetic and metabolic studies on PAH assimilation are fundamental and significant for better understanding of PAH biodegradation pathways, and to assemble and engineer bioprocessing plans to get better degradation competence. In the present article, a comprehensive description is offered on the kinetic and metabolic aspects of acenaphthene assimilation pathway by Sphingobacterium sp. strain RTSB, which follows the first-order 
reaction kinetics. The experimental results indicated that apart from the alteration in temperature, $\mathrm{pH}$ value, and substrate concentration, acenaphthene biodegradation by the strain RTSB is also influenced by the metabolic regulation and on the gathering of growth inhibitory metabolites, for instance, 1-naphthoic acid. Therefore, the kinetic and metabolic aspects of acenaphthene assimilation by the Sphingobacterium sp. strain RTSB are interesting, which may offer a superior option for microbial choice in the bioremediation of PAHs and/or other toxic organic pollutants.

Conflict of interest: The author declares no conflict of interest.

1. Marston, C. P., Pereira, C., Ferguson, J., Fischer, L., Hedstrom, O., Dashwood, W. M. and Barid, W. M., Effect of a complex environmental mixture from coal tar containing polycyclic aromatic hydrocarbons $(\mathrm{PAH})$ on tumor initiation, PAH-DNA binding and metabolic activation of carcinogenic $\mathrm{PAH}$ in mouse epidermis. Carcinogenesis, 2001, 22, 1077-1086.

2. Mastrangelo, G., Fadda, E. and Marzia, V., Polycyclic aromatic hydrocarbons and cancer in man. Environ. Health Perspect., 1996, 104, 1166-1170.

3. Xue, W. and Warshawsky, D., Metabolic activation of polycyclic and heterocyclic aromatic hydrocarbons and DNA damage: a review. Toxicol. Appl. Pharmacol., 2005, 206, 73-93.

4. Habe, H. and Omori, T., Genetics of polycyclic aromatic hydrocarbon metabolism in diverse aerobic bacteria. Biosci. Biotechnol. Biochem., 2003, 67, 225-243.

5. Kanaly, R. A. and Harayama, S., Biodegradation of high molecular weight polycyclic aromatic hydrocarbons by bacteria. J. Bacteriol., 2000, 182, 2059-2067.

6. Pothuluri, J. V. and Cerniglia, C. E., Microbial metabolism of polycyclic aromatic hydrocarbons. In Biological Degradation and Bioremediation of Toxic Chemicals (ed. Chaudhry, R. G.), Chapman \& Hall, London, 1994, pp. 92-124.

7. Shuttleworth, K. L. and Cerniglia, C. E., Environmental aspects of PAH biodegradation. Appl. Biochem. Biotechnol., 1995, 54, 291302 .

8. Tortella, G. R., Diez, M. C. and Duran, N., Fungal diversity and use in decomposition of environmental pollutants. Crit. Rev. Microbiol., 2005, 31, 197-212.

9. Keith, L. H. and Telliard, W. A., Priority pollutants I-a perspective view. Environ. Sci. Technol., 1979, 13, 416-423.

10. Schocken, M. J. and Gibson, D. T., Bacterial oxidation of polycyclic aromatic hydrocarbons acenaphthene and acenaphthylene. Appl. Environ. Microbiol., 1984, 48, 10-16.

11. Windholz, M. et al., An encyclopedia of chemicals, drugs, and biological. In The Merck Index (eds O’Neil, M. J. et al.), Merck and Co. Inc., New Jersey, USA, 1983, 10th edn.

12. Chapman, P. J., Degradation mechanisms. In Proceedings of the Workshop: Microbial Degradation of Pollutants in Marine Environments (eds Bourquin, A. W. and Pritchard, P. H.), Gulf Breeze, U.S. Environmental Protection Agency, 1979, pp. 28-66.

13. Ellis, B., Harold, P. and Kronberg, H., Bioremediation of a creosote contaminated site. Environ. Technol., 1991, 12, 447-459.

14. Geiselbrecht, A. D., Hedlund, B. P., Tichi, M. A. and Staley, J. T., Isolation of marine polycyclic aromatic hydrocarbon (PAH)degrading Cycloclasticus strains from the Gulf of Mexico and comparison of their PAH degradation ability with that of Puget Sound Cycloclasticus strains. Appl. Environ. Microbiol., 1998, 64, 4703-4710.
15. Ghosal, D., Dutta, A., Chakraborty, J., Basu, S. and Dutta, T. K., Characterization of the metabolic pathway involved in assimilation of acenaphthene in Acinetobacter sp. strain AGAT-W. Res. Microbiol., 2013, 164, 155-163.

16. Hedlund, B. P., Geiselbrecht, A. D., Bair, T. J. and Staley, J. T., Polycyclic aromatic hydrocarbon degradation by a new marine bacterium, Neptunomonas naphthovorans gen. nov., sp. nov. Appl. Environ. Microbiol., 1999, 65, 251-259.

17. Kafilzadeh, F. et al., Isolation and identification of carcinogen acenaphthene-degrading endemic bacteria from crude oil contaminated soils around abadan refinery. J. Fasa. Univ. Med. Sci., 2012, 2, 181-186.

18. Komatsu, T., Omori, T. and Kodama, T., Microbial degradation of polycyclic aromatic hydrocarbons acenaphthene and acenaphthylene by a pure bacterial culture. Biosci. Biotechnol. Biochem., 1993, 57, 864-865.

19. Mallick, S., Biodegradation of acenaphthene by Sphingobacterium sp. strain RTSB involving trans-3-carboxy-2-hydroxybenzylidenepyruvic acid as a metabolite. Chemosphere, 2019, 219, 748-755.

20. Pinyakong, O., Habe, H., Kouzuma, A., Nojiri, H., Yamane, H. and Omori, T., Isolation and characterization of genes encoding polycyclicaromatic hydrocarbon dioxygenase from acenaphthene and acenaphthylene degrading Sphingomonas sp. strain A4. FEMS Microbiol. Lett., 2004, 238, 297-305.

21. Salam, L. B., Obayori, O. S. and Hawa, O., Hydrocarbon degradation and biosurfactant production by an acenaphthene-degrading Pseudomonas species. Soil Sediment Contam., 2016, 25, 837-856.

22. Selifonov, S. A. et al., Isolation and characterization of (1)-1,1adihydroxy-1-hydrofluoren-9-one formed by angular dioxygenation in the bacterial catabolism of fluorine. Biochem. Biophys. Res. Commun., 1993, 193, 67-76.

23. Shi, T., Fredrickson, J. K. and Balkwill, D. L., Biodegradation of polycyclic aromatic hydrocarbons by Sphingomonas strains isolated from the terrestrial subsurface. J. Ind. Microbiol. Biotechnol., 2001, 26, 283-289.

24. Mallick, S., A review on origin, occurrence and biodegradation of polycyclic aromatic hydrocarbon acenaphthene. Appl. Ecol. Environ. Sci., 2019, 7, 263-269.

25. Selifonov, S. A. et al., Oxidation of naphthenoaromatic and methyl-substituted aromatic compounds naphthalene-1,2-dioxygenase. Appl. Environ. Microbiol., 1996, 62, 507-514.

26. Lowry, O. H. et al., Protein measurement with the Folin phenol reagent. J. Biol. Chem., 1951, 193, 265-267.

27. Simkins, S. and Alexander, M., Models for mineralization kinetics with the variables of substrate concentration and population density. Appl. Environ. Microbiol., 1984, 47, 1299-1306.

28. Guerin, W. F. and Jones, G. E., Two-stage mineralization of phenanthrene by estuarine enrichment cultures. Appl. Environ. Microbiol., 1988, 54, 929-936.

29. Tian, L., Ma, P. and Zhong, J. J., Kinetics and key enzyme activities of phenanthrene degradation by a new phenanthrenedegrading strain Pseudomonas mendocina. Process Biochem., 2002, 37, 1431-1437.

30. Tian, L., Ma, P. and Zhong, J. J., Impact of the presence of salicylate or glucose on enzyme activity and phenanthrene degradation by Pseudomonas mendocina. Process Biochem., 2003, 38, 1125-1132.

ACKNOWLEDGEMENTS. I acknowledge Dr Tapan K. Dutta, Bose Institute, Kolkata for providing instrumental and laboratory facilities. This study was supported by the University Grants Commission of India.

Received 24 October 2019; revised accepted 6 November 2020

doi: $10.18520 / \mathrm{cs} / \mathrm{v} 120 / \mathrm{i} 5 / 926-931$ 